\title{
LETTERS
}

\section{Sudden cardiac death and ethnicity}

I read with interest the article by Drs. Fanous and Dorian on the prevention and management of sudden cardiac arrest and/or death (SCD) in athletes. ${ }^{1}$ As a pediatrician and pediatric pathologist, I have come across a few of these rare events during my career. It is indeed one of the most tragic events a physician can experience. The child is full of vitality and at the start of life, and suddenly everything collapses not only for them, but also for their parents and friends.

Although SCD is not always associated with underlying cardiac pathology, pathologists, who are experts in dissecting congenital heart disease, remain crucial, notwithstanding the molecular biology investigations of ion channels. ${ }^{2}$

Recently, Kong and colleagues conducted a meta-analysis to assess the mean allele frequencies of channelopathy genes SCN5A, NOS1AP, KCNH2, KCNE1 and KCNQ1 among black, white, Asian and Hispanic people. ${ }^{3}$ They found that Asian people had the highest overall mean allele frequencies of NOS1AP and SCN5A. Conversely, white people had the highest $\mathrm{KCNH} 2$ frequency, and Hispanic people the highest KCNQ1 frequency.

The Exome Aggregation Consortium (ExAC) describes the aggregation and analysis of high-quality exome (protein- coding region) DNA sequence data for more than 60000 individuals belonging to diverse ancestries. ${ }^{4}$ These data can be used for both the filtering of candidate disease-causing variants and the identification of variants in protein-coding genes. The ExAC data seem to be in agreement with the results of the meta-analysis by Kong and colleagues, indicating that Asian people carry the most alleles of genes associated with SCD. ${ }^{3}$

Channelopathies and ethnicity seem to be connected. This should be kept in mind by physicians and policy regulators.

\section{Consolato M. Sergi MD PhD}

Anatomic pathologist, University of Alberta, Edmonton, Alta.

- Cite as: CMAJ 2019 November 11;191:

E1254. doi: 10.1503/cmaj.73297

\section{References}

1. Fanous $\mathrm{Y}$, Dorian $\mathrm{P}$. The prevention and management of sudden cardiac arrest in athletes. CMAJ 2019;191:E787-91.

2. Cann F, Corbett M, O'Sullivan D, et al. Phenotype-driven molecular autopsy for sudden cardiac death. Clin Genet 2017;91:22-9.

3. Kong T, Feulefack J, Ruether K, et al. Ethnic differences in genetic ion channelopathies associated with sudden cardiac death: a systematic review and meta-analysis. Ann Clin Lab Sci 2017;47: 481-90.

4. Lek M, Karczewski KJ, Minikel EV, et al. Analysis of protein-coding genetic variation in 60,706 humans. Nature 2016;536:285-91.

Competing interests: None declared. 